\title{
Temperature Effects on Mechanical Properties of Woven Thermoplastic Composites for Secondary Aircraft Structure Applications
}

\author{
Yue Wang, Jipeng Zhang, Jiazhen Zhang and Zhengong Zhou \\ Center for Composite Materials and Structures, Harbin Institute of Technology, 15001 Harbin, China
}

\begin{abstract}
The effect of temperature on the mechanical behavior of 8-H satin woven glass fabric/polyethylene sulfide (GF/PPS) was investigated in this paper. Static-tensile tests were both conducted on notched and unnotched specimens at typical temperatures (ambient, $95^{\circ} \mathrm{C}$ and $125^{\circ} \mathrm{C}$ ) based on the glass transition temperatures $\left(T_{\mathrm{g}}\right)$ of the neat resin and composite, their strength and moduli were obtained and compared. The damage patterns of failed specimens of notched and unnotched were examined with the aid of high-definition camera and stereomicroscope. The results of stress-strain relationships showed that the slight nonlinearity of the curves were observed for these two specimens, which was associated with the plastic deformation of localized resin. The damage patterns of notched and unnotched specimens at different temperatures proved that damage and plastic deformation were two simultaneous mechanisms and it was prominent in the notched. It was the overstress accommodation mechanism that led to a relative high strength rentention for the notched and a reduction of the hole sensitivity. The results obtained in this paper indicated that GF/PPS can be used as secondary aircraft structures at elevated temperatures higher than its $T_{\mathrm{g}}$.
\end{abstract}

\section{Introduction}

"Light weight and high strength" is always the goal for the aircraft manufacturers and scientists. Composite materials have gained widely attentions due to the prominent advantages of weight reduction and improved durability compared to metals [1]. At present, the fraction of usage amount of composites to the total weight of aircrafts has been an important criterion for evaluating the progressiveness of civil aircrafts. For example, the composite materials make up $25 \%, 52 \%$ and $50 \%$ of the structural mass of A380, A350 and Boeing 787, respectively [2]. Despite thermosetting resin-based composite materials are regarded as the favored materials in designing structures, the use of high-performance thermoplastic composites is continuously increasing because of the advantages of unlimited shelf life, recyclability and improved processing technologies over conventional thermosetting composites [3]. In addition, excellent damage tolerance, corrosion and impact resistance they offered further expand their application fields. Until now, thermoplastic composites have been used as wing fixed leading edges, ribs, clips, angles and cleats [4], as Figure 1 shown. In oder to make full use of thermoplastic composites, they are considered as candidates for special aircraft structures, such as aircraft engine nacells that subjected to thermal effect in service, and it is necessary to clarify their mechanical responses and damage patterns at elevated temperatures, expecially when the environment temperature is higher than the glass transion temperature of the composite.

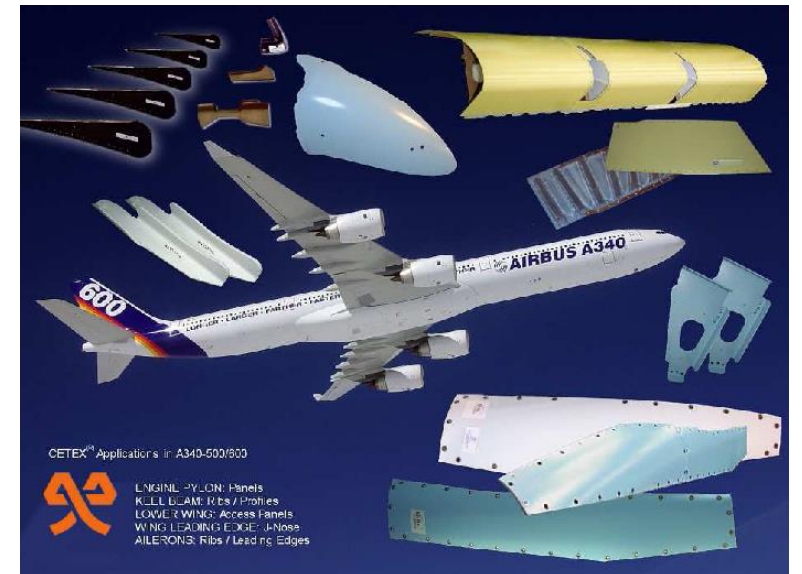

Figure 1. Application of PPS composites in Airbus A340 supplied by TenCate Compony

The glass transition temperature is a critical temperature that amorphous phase of the polymer shifts from glass state to rubbery state. For the fiber reinforced polymer composites, the effect of $T_{\mathrm{g}}$ is always characterized by nonlinear behavior, especially for offaxial plies [4]. The nonlinear response is attributed to the shear deformation of the polymer matrix along the fibers, which will be enhanced at $T>T_{\mathrm{g}}$. Some researchers investigated the mechanical properties of thermoplastic composites at elevated temperatures, comprsing of tensile, compressive, flexural and fatigue properties [5-8]. Most of them found that both of the strength and modulus present an obvious decline trend when the temperature was around $T_{\mathrm{g}}$. But all of them focused the glass 
transition temperature of composite $\left(T_{\mathrm{g}}^{\mathrm{c}}\right)$, and that of the neat resin $\left(T_{g}^{r}\right)$ also plays a dominant role in mechanical response.

Furthermore, it is inevitable to drill holes when the thermoplastic composites are used in joint structures, such as angles and cleats. Then the failure behavior of the notched specimen will be dominated by the damage around the hole due to the stress concentration. Reference [9-11] investigated the notched tensile behavior and gave a deep insight into damage progression in the vicinity of the hole. They observed that the inital damage generated from the edge of the hole, leading to a redistribution of stress. Even at elevated temperatures, two simultaneous mechanisms of damage and plastic deformation will result in a more complex failure behavior [12].

In view of this, the tensile properties of notched and unnotched woven GF/PPS composite were investigated experimentally. The research is focused on the comparison of mechanical response and damage patterns between the two components at typical temperatures.

\section{Materials and methods}

\subsection{Materials}

The composite material in this work was a thermoplastic 8-harness satin weave composite laminate supplied by TenCate Advanced Composites, which has EC9 glassfibre fabric as reinforcement and Fortron 0214 PPS as a matrix. The volume fraction of fibers is $52.5 \%$ in GF/PPS laminate. The composite laminate was manufactured using hot pressing technique according to a quasi-isotropic lay-up: $\quad[( \pm 45) /(0,90) /( \pm 45) /(0,90)]_{2 \mathrm{~s}}$. Sixteen plies were stacked in the laminate and a thickness of $3.84 \mathrm{~mm}$ was obtained.

\subsection{Methods}

Static tensile tests were performed on Instron 5569 universal mechanical testing machine, which was equipped with a $50 \mathrm{kN}$ capacity load cell and an environmental chamber. Tests on unnotched and notched specimens were carried out according to ASTM D3039 and ASTM D5766, respectively. The tests were conducted in displacement control mode at a same crosshead speed of $1 \mathrm{~mm} / \mathrm{min}$. In order to obtain the whole strains of the specimens, laser extensometer and strain gauge were used in notched and unnotched tensile tests, respectively. The geometries of specimens are shown in Figure 2.

Prior to the mechanical testing, a combination of thermal analyses was used to establish a relationship between the thermal property and mechanical property. A differential scanning calorimetry performed by Pyris Diamond DSC was conducted on the GF/PPS composite. Both the heating and cooling rate used were $10{ }^{\circ} \mathrm{C} / \mathrm{min}$. Three-point bending dynamic mechanical analysis was carried out by Perklin Elmer Pyris Diamond DMA. Temperature scans from room temperature to $250{ }^{\circ} \mathrm{C}$ at a heating rate of $5^{\circ} \mathrm{C}$ and the test was performed in Nitrogen atmosphere with a frequency of $1 \mathrm{~Hz}$.

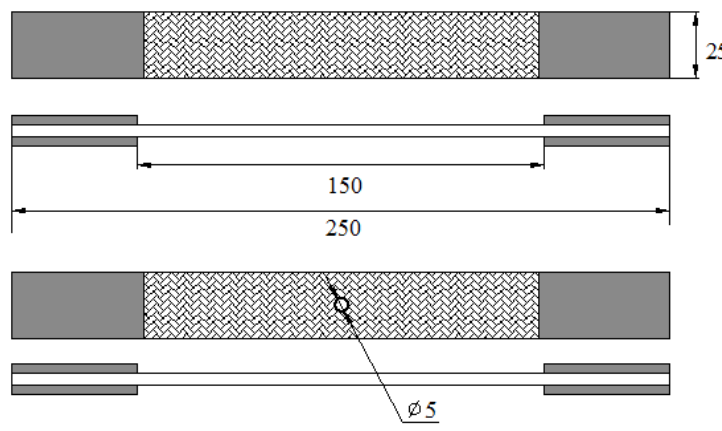

Figure 2. Geometries of the specimens. (Dimensions in $\mathrm{mm}$ )

\section{Results and discussion}

\subsection{Thermal analysis of GF/PPS composite}

The glass transition temperature $\left(T_{g}^{c}=101^{\circ} \mathrm{C}\right)$ is obtained by DMA, and the crystallinity $(52 \%)$ is calculated by DSC using a value of heat of fusion of a $100 \%$ crystalline sample of PPS of $76.5 \mathrm{~J} / \mathrm{g}$, as shown in Figure 3. It is nearly the same with [1] and the tiny difference is probably due to the type of reinforced fibres. According to TenCate material parameter, $T_{g}^{r}=90^{\circ} \mathrm{C}$ is obtained for neat resin. The deviation of the crystalline peak and the improvement of glass transition temperature are mainly attributed to the addition of fibres.
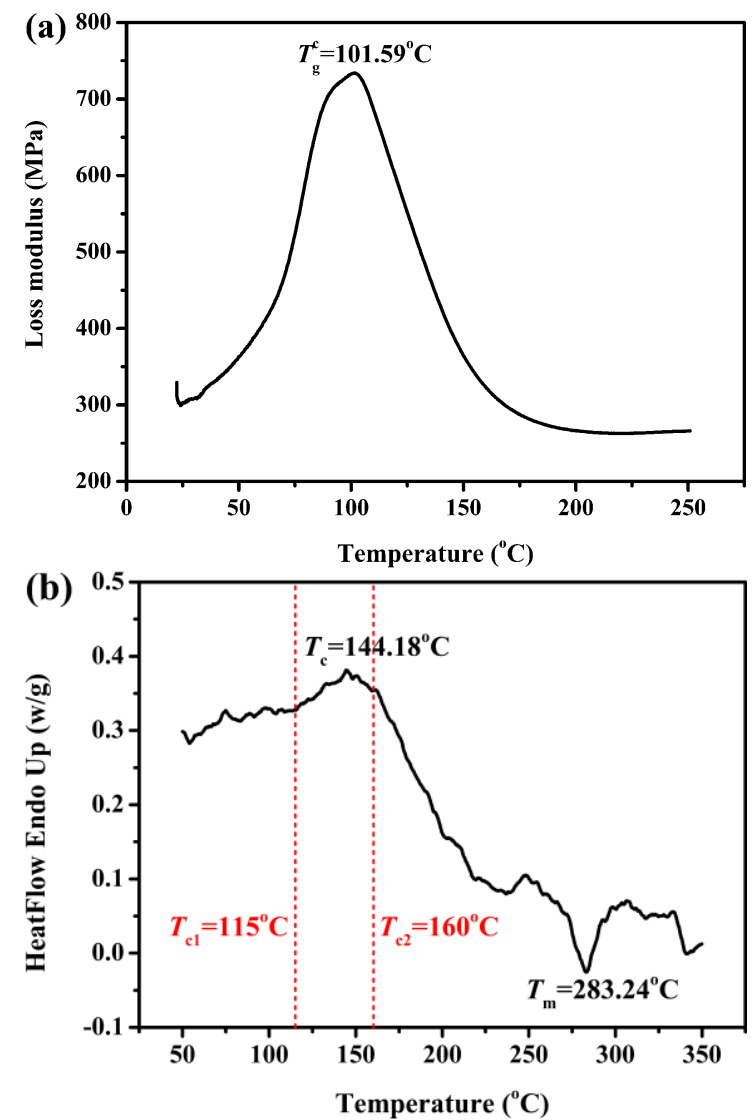

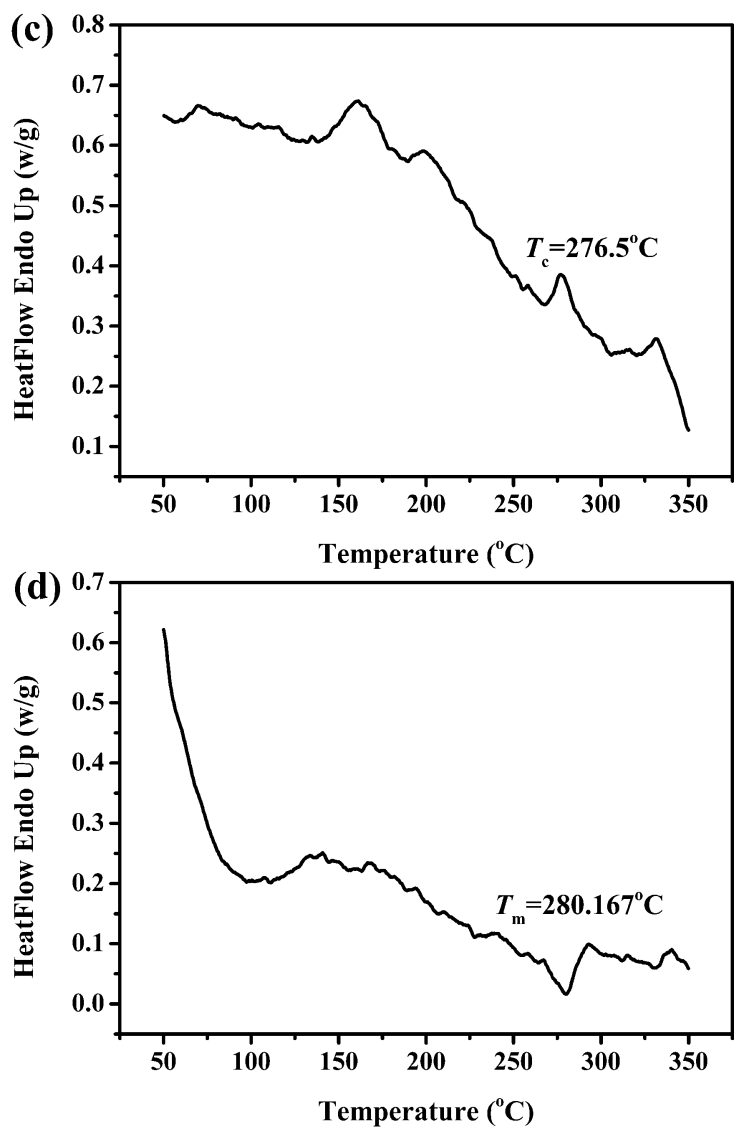

Figure 3. DMA and DSC curves of GF/PPS composite: (a) loss modulus curve obtianed by DMA; (b) first heating cycle, (c) cooling cycle and (d) second heating cycle. (b), (c) and (d) were obtained by DSC measurement. $\left(T_{\mathrm{g}}, T_{\mathrm{c}}\right.$ and $T_{\mathrm{m}}$ denote glass transition temperature, crystallization temperature and melting temperature. $T_{1}$ and $T_{2}$ denote the temperature of the initiation and end of the peak.)

\subsection{Stress strain relationships}

The whole strain of a notched specimen can not be obtained by strain gauge due to the stress concertration in the vicinity of the hole, thus a laser extensometer is in needed. In order to make the strain accurate, a calibrating experiment was conducted on the unnotched specimen at $95^{\circ} \mathrm{C}$ considering the effect of temperature, then the result is shown in Figure 4.

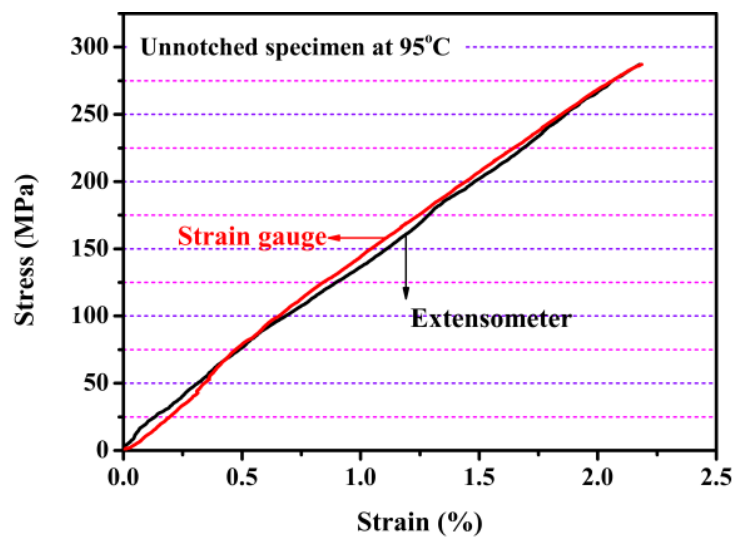

Figure 4. Strain calibration between extensometer and strain gauge.
It can be found that both of the two stress-strain curves obtained by extensometer and strain gauge are consistent and they also present some fluctuations while the extensometer one is more obvious. The reason for this may be associated with the slight plasitc deformation in $\left( \pm 45^{\circ}\right)$ ply at the surface of the specimen.
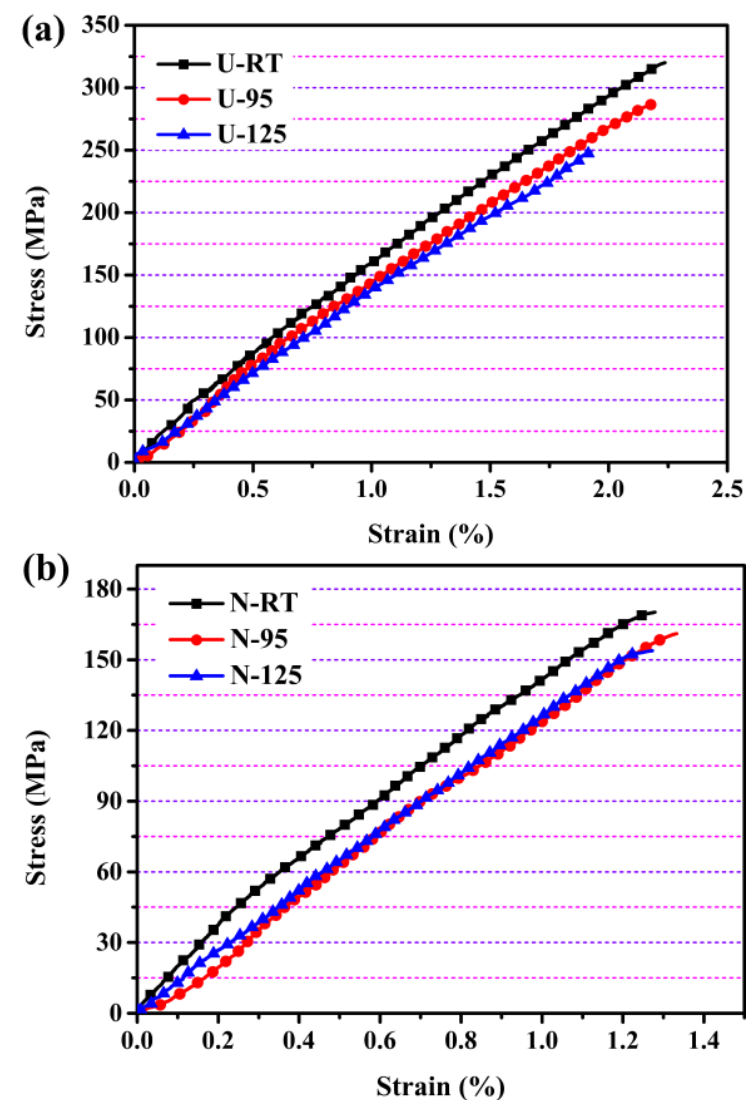

Figure 5. Stress-strain relationships at typical temperatures: (a) unnotched; (b) notched.

The axial tensile tests were conducted on nothed and unnotched specimens at $\mathrm{RT}, 95^{\circ} \mathrm{C}$ and $125^{\circ} \mathrm{C}$, the results are shown in Figure 5. For the unnotched specimens, the stress-strain curve is almost linear at RT, which is similar with CF/PPS [13] and GF/epoxy [9], indicating that the polymer chains are frozen and the matrix is brittle at this temperature. When temperature reaches $95^{\circ} \mathrm{C}$ ( $T_{g}^{c}>T>T_{g}^{r}$ ), the curve present a low degree of nonlinearity as the load increasing which is related with the characteristic of weave fabric and $\left( \pm 45^{\circ}\right)$ plies. During the manufacturing of the fabric, crimps were formed at the crossovers of weft and warp fiber bundles while lots of resin-rich regions are also formed around the crimps during the hot pressing. Part of the resin in these regions are far away from fibers so that the glass transition temperature of the resin is still the same with $T_{g}^{r}$ [14]. Thus, the slight nonlinearity of the curve is resulted from the plastic deformation of the localized resin in the resinrich regions and $\pm 45^{\circ}$ oriented plies. At $125^{\circ} \mathrm{C}$, the stressstrain curve is very closed to the one at $95^{\circ} \mathrm{C}$, but the nonlinearity is more obvious due to the softening of matrix. In addition, a fluctuation is observed near the end of the curve, which is associated with the straightening of warp fiber in the loading direction [15]. In general, for 
the fiber reinforced polymers, the majority of tensile load are carried by $0^{\circ}$ fibers, which results in a temperatureindependent behavior [12].

For the notched specimens, the stress state is more complex than the unnotched due to the presence of a hole. As can be seen in Figure 5(b), the stress-strain curve of the notched specimen at RT present a similar linear trend as that of the unnotched one in spite of some fluctuations. While a low degree of nonlinearity is observed near the end, it is suggested that some damage generate before the final fracture. It is worth noting that the curves of notched specimens at $95^{\circ} \mathrm{C}$ and $125^{\circ} \mathrm{C}$ are nearly the same with a higher stress in former, and both of the two curves exhibit obvious nonlinearity near the end. As mentioned above, although the plastic deformation of matrix occures at $T>$ $T_{\mathrm{g}}$, it has a weak influence on the mechanical response. Accordingly, the enhancement of the nonlinearity of the curves are resulted from the damage progression in the vicinity of the hole.

\subsection{Damage patterns}

In order to investigate the effect of temperature on the damage patterns of the notched and unnotched specimens and make a comparison between the two components, the failed specimens were examined with the aid of highdefinition camera and stereomicroscope, the results are shown in Figure 6. For the unnotched specimens, the specimens at RT failed in a brittle mode, which are characterized by fibre bundles fracture and little amount of delamination at the surface ply where a higher interlaminar stress usually presents [9]. Judging from the extent and degree of damage, the initial damage is generated from the free edge. This is consistent with [15], transverse weft cracking and fibre fracture that obtained by scanning electronic microscope led to the final fracture, and meanwhile the damage was observed at a relative high applied load close to the specimen fracture. This is the reason why slight nonlinearity is observed at the end of the stress-strain curve. When temperature increases to $95^{\circ} \mathrm{C}$, the specimen fails in two parts and some filaments are present, as well as a bulge originated from delaminations and splitting. This phenomenon

indicates that the increase of temperature enhances the ductility of matrix and weakens the fibre-matrix interface property. Whereas four specimens are tested at $125^{\circ} \mathrm{C}$ and they all failed near the tabs, the damage patterns present in Figure 5 are considered as reference which also exhibit a large amount of delaminations.

For the notched specimens, the damage patterns are substantially different from the unnotched ones, reflecting in the damage zone limited in the vicinity of the hole. The damage patterns of the specimen at RT are characterized by axial fibres fracture and a small amount of delaminations. As some publications about the damage progression of the notched specimen reported, transverse cracks as the initial damage generated from the edge of the hole and then propagated [10]. Thus, all of the notched specimen present transverse failure in Figure 6. As temperature increases, both of the length and the number of fibres pulled out increase, as well as splitting and delamination. Besides, part of fibres of notched specimen at $125^{\circ} \mathrm{C}$ rotate to the loading direction, which suggests the damage progression and plastic deformation are simultaneous at this condition.

\subsection{Comparisons of mechanical response}

Comparisons of strength and modulus have been made between notched and unnotched specimens as functions of temperature, the results are shown in Figure 7. It can be found that both of the ultimate tensile strength of the two components present decline trend as temperature increasing, especially at $T>T_{g}^{c}$, the strength decrease faster due to the softening of matrix. In addition, it should be noted that the tensile strength retention rate at $95^{\circ} \mathrm{C}$ and $125^{\circ} \mathrm{C}$ are $91 \%$ and $78 \%$ for the unnotched specimen. The relative lower retention of the latter may be originated from the effect of the tabs, although the tests at $95^{\circ} \mathrm{C}$ tell an error of $1 \%$ between the specimens that fractured at different locations. In spite of this, the strength retention rates of $93 \%$ and $90 \%$ for the notched are still higher than the unnotched. As mentioned in Section 3.3, the damage and plastic deformation in the vicinity of the hole plays an important role in the overstress accomdation.

$9^{\circ} \mathrm{C}$
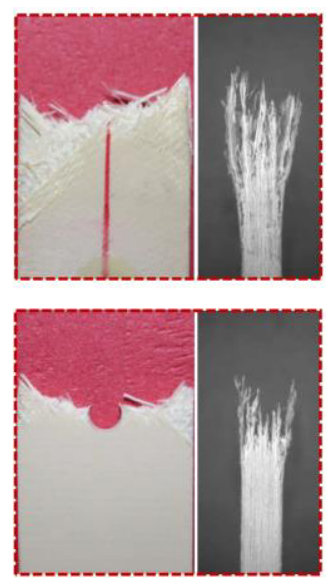

$125^{\circ} \mathrm{C}$
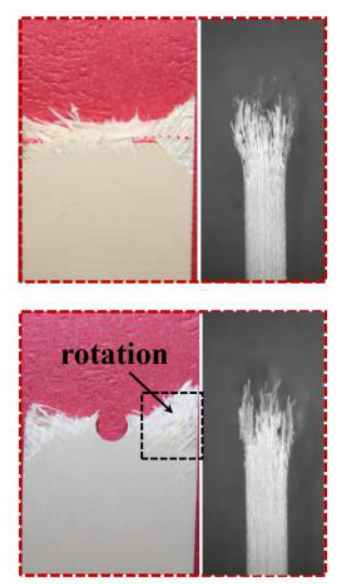

Figure 6. Damage patterns of notched and unnotched specimens at different temperatures. 
The hole factor $C_{\mathrm{h}}$ reprensents the hole sensitivity of the laminate ultimate strength. Its definition is

$$
C_{\mathrm{h}}=\frac{\sigma_{\mathrm{u}}^{\text {notched }}}{\sigma_{\mathrm{u}}^{\text {unnotched }}}
$$

where

$$
\begin{aligned}
\sigma_{\mathrm{u}}^{\text {notched }} & =\frac{F_{\mathrm{u}}^{\text {notched }}}{t \cdot w} \\
\sigma_{\mathrm{u}}^{\text {unnotched }} & =\frac{F_{\mathrm{u}}^{\mathrm{unnotched}}}{t \cdot w}
\end{aligned}
$$

Among them, $\sigma_{\mathrm{u}}^{\text {notched }}$ and $\sigma_{\mathrm{u}}^{\mathrm{unnotched}}$ denote ultimate tensile stress for the notched and unnotched specimens, $t$ and $w$ are thickness and width. As can be seen in Figure $7(\mathrm{a}), C_{\mathrm{h}}$ increases obviously as temperature increasing, which indicates that the delamination and splitting at elevated tempertures make a contribution to stress relief. Moreover, the softening of matrix and damage progression in the vicinity of hole also make an effect on the reduction of hole sensitivity (being the reverse of the hole factor).
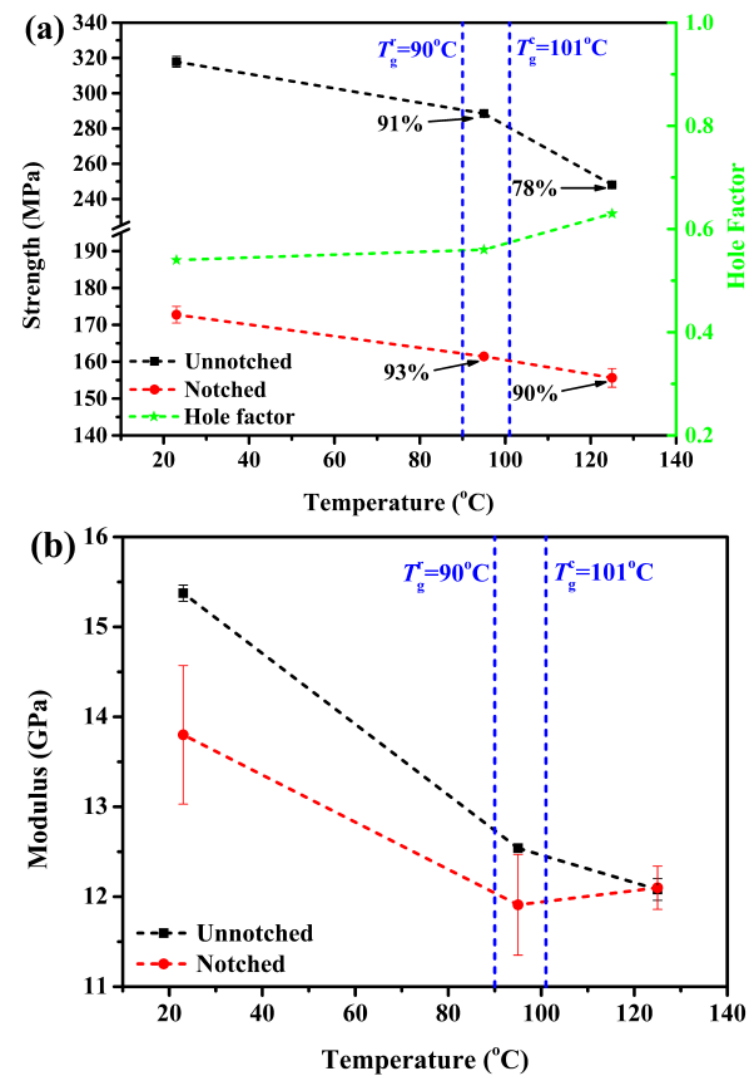

Figure 7. Mechanical response of CF/PPS as a function of temperature: (a) strength; (b) modulus.

It is expected that the modulus would present a similar trend with the strength, but it is found that the modulus of the notched specimen at $125^{\circ} \mathrm{C}$ is higher than that at $95^{\circ} \mathrm{C}$, while the modulus of the unnotched specimen only present a slightly decrease at $125^{\circ} \mathrm{C}$ than $95^{\circ} \mathrm{C}$. This is consistent with [15] and [7], the modulus start increasing in the $120^{\circ} \mathrm{C}-130^{\circ} \mathrm{C}$ temperature range, probably due to the cold crystallization at $125^{\circ} \mathrm{C}$. Actually, it is observed in Figure 3(b) that a crystallization peak exsit at $115^{\circ} \mathrm{C}-160^{\circ} \mathrm{C}$ and in this temperature range, a crystallization phenomenon of the amorphous phase of the polymer occurs, leading to an increase on crystallinity as well as the tensile modulus.

\section{Conclusions}

The temperature dependence of tensile properties for notched and unnotched $8-\mathrm{H}$ satin woven GF/PPS were investigated at typical temperatures based on the glass transition temperatures of the neat resin and composite. The results obtained can be concluded as follows:

(1) The nonlinearity of the stress-strain curves for unnotched and notched specimens was enhanced as temperature increasing, which was mainly associated with plastic deformation of localized resin in the resinrich regions and $\left( \pm 45^{\circ}\right)$ plies. and For the notched specimens, the nonlinearity observed at the end of the curves was dominated by the initiation of damage in the vicinity of the hole.

(2) With increase in temperature, the damage patterns transformed from brittle mode to ductility mode, reflecting in the increase of delamination, splitting and fibres pulled out, which suggested the fibre-matrix interface bonding strength was weakened. For the notched specimens, part of fibres located in $\left( \pm 45^{\circ}\right)$ plies rotated to the loading direction at $125^{\circ} \mathrm{C}$, indicating that damage and plastic deformation were two simultaneous mechanisms which dominated specimens fractured.

(3) Obvious reduction of strength can be found for the two components due to the softening of matrix, especially $T>T_{\mathrm{g}}^{\mathrm{c}}$ the strength decreased fast. While it is relative gradual for the notched attributed to the overstress accomodation mechanism, leading to a reduction of hole sensitivity. Besides, the modulus decreased firstly and then slightly increased at $125^{\circ} \mathrm{C}$, it was related with cold crystallization. Finally, the relative high strength retention suggested that GF/PPS can be used at elevated temperatures higher than its $T_{\mathrm{g}}$ under static loadings.

\section{Acknowledgement}

The present work was supported by the National Science Foundation of China under Grant Nos. 51271067, 11272105 and 11572101.

\section{References}

1. P. Carnevale, Fiber-matrix Interfaces in Thermoplastic Composites $(\mathrm{PhD}$, Delft University of Technology, 2014)

2. S.Y. Du, Z.D. Guan, Acta Mater. Compos. Sin. 25, 2 (2008)

3. D.R. Meyer, P. Carnevale, H.E.N. Bersee, Plast. Rubber Compos. Macromol. Eng. 39, 122 (2010)

4. W. Albouy, B. Vieille, L. Taleb, Compos. Part A 49, 165 (2013)

5. B. Vieille, J. Aucher, L. Taleb, Mater. Des. 35, 707 (2012)

6. J.A. Grape, V. Gupta, Mech. Mater. 30, 165 (1998) 
7. D.R. Meyer, H.E.N. Bersee, A. Beukers, 49th Structures, Structural Dynamics, and Materials Conference (Schaumburg, America, 2008)

8. L.A.L. Franco, M.L.A. Grac, F.S. Silva, Mater. Sci. Eng. A 488, 505 (2008)

9. R.M. O’Higgins, M.A. McCarthy, C.T. McCarthy, Compos. Sci. Technol. 68, 2770 (2008)

10. F. Pierron, B. Green, M.R. Wisnom, S.R. Hallett, Composites Part A 28, 2321 (2007)

11. E.V. Iarve, D. Mollenhauer, R. Kim, Composites Part A 36, 163 (2005)

12. B. Vieille, L. Taleb, Compos. Sci. Technol. 71, 998 (2011)
13. S. Daggumati, I.D. Baere, W.V. Paepegem, J. Degrieck, J. Xu, S.V. Lomov, I. Verpoest, Compos. Sci. Technol. 74, 20 (2013)

14. B.M. Walther, An Investigation of the Tensile Strength and Stiffness of Unidirectional Polymer-Matrix, Carbon-Fiber Composites under the Influence of Elevated Temperatures (Master, Virginia Polytechnic Institute and State University, 1998)

15. S. Rasool, Fatigue of woven thermoplastic composites the effect of the fibre matrix interface (PhD, Delft University of Technology, 2015) 